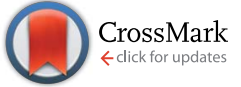

Cite this: RSC Adv., 2017, 7, 8677

Received 7th January 2017

Accepted 23rd January 2017

DOI: 10.1039/c7ra00250e

rsc.li/rsc-advances

\section{The synthesis and mechanistic studies of a highly active nickel phosphide catalyst for naphthalene hydrodearomatization $\uparrow$}

\begin{abstract}
Guoxia Yun, ${ }^{a}$ Qingxin Guan*a and Wei Li*ab
Although HDS and HDN reactions over transition metal phosphides have been widely studied, few publications about aromatic hydrodearomatization (HDA) over transition metal phosphides are found. Using ordered mesoporous Al-MCM-41 (Al-M) as the support, a series of supported nickel phosphide catalysts with different Ni/P molar ratios and loadings have been prepared by a temperatureprogrammed reduction and characterized. The HDA activity of naphthalene was measured in a fixed bed reactor at $250-330{ }^{\circ} \mathrm{C}$ and $3 \mathrm{MPa}$. The results showed that the catalyst with initial Ni/P molar ratio of 1.25 and $15 \mathrm{wt} \%$ loading displayed the highest HDA activity as well as $99.0 \%$ of selectivity of decalin at $270{ }^{\circ} \mathrm{C}$, which is even higher than that of $0.5 \mathrm{wt} \% \mathrm{Pt}-\mathrm{Al}-\mathrm{M}$ catalyst. As a comparison, the HDA performance of various catalysts was also examined. The results revealed that the presence of framework aluminum favors HDA processes and a synergistic effect between nickel phosphide and the suitable acidity resulted in an improvement of the catalytic activity. Finally, the possible reaction pathway of naphthalene hydrogenation (HYD) on nickel phosphide catalysts was proposed. Taking into consideration the high catalytic activity, Al-M supported nickel phosphide can be considered as a very efficient HDA catalyst to decrease the contents of aromatics in the fuels.
\end{abstract}

\section{Introduction}

Population increase, urbanization, and rising living standards have rapidly increased global energy consumption and environmental burdens in the last half century. Energy consumption is expected to continue to increase dramatically in the coming years along with its associated environmental issues. Thus more stringent environmental regulations and fuel specifications on diesel are being tightened in both the United States and Europe, which not only put impelling emphasis on the contents of aromatics in the fuels, but also lay special focus on the density and cetane number. ${ }^{1}$ Because aromatics in fuels, i.e., diesel and jet fuels, not only lower the quality and produce undesired exhaust emissions but also have potentially hazardous and carcinogenic effects. ${ }^{2}$ Therefore, HYD of aromatics becomes one of the most important unit operations in modern oil-refinery and conventional hydroprocessing technology is used to reduce aromatics in fuels through the HDA reaction. And HYD can produce cycloalkane from aromatics and

${ }^{a}$ College of Chemistry, Key Laboratory of Advanced Energy Materials Chemistry (Ministry of Education), Nankai University, Tianjin, 300071, China.E-mail:weili@ nankai.edu.cn; qingxinguan@nankai.edu.cn

${ }^{b}$ Collaborative Innovation Center of Chemical Science and Engineering, Tianjin, 300071, China

$\dagger$ Electronic supplementary information (ESI) available. See DOI: 10.1039/c7ra00250e thus significantly improve the cetane number of diesel streams and improve the combustion characteristics. The products of aromatics HYD are considered as an ideal component of jet fuel, as they have concurrently appropriate quality and volume caloric value. In this regard, this opinion is consistent with that of Yan et al. They highlight a detailed overview of the development related to energy production and environmental remediation. $^{3}$

Generally, HYD is a highly exothermic reaction and thus thermodynamically favored at lower temperature. A lot of information about naphthalene HYD and formation of decalin have been reported in literature. ${ }^{4}$ Therefore, searching out excellent HYD catalysts will provide potentiality for decreasing the aromatic content in the fuels and regarding them as high thermal stable jet fuel. Conventional catalysts in aromatic HYD are sulfides based on Mo or $\mathrm{W}$ and promoted with $\mathrm{Ni}$ or Co supported on alumina. ${ }^{5}$ The drawbacks of these catalysts include severe operating conditions such as high temperature and high pressure. Furthermore, only moderate levels of saturation of aromatic content under typical hydrotreating conditions can be obtained due to equilibrium limitations. Meanwhile, as proposed by Wang and Zhou et al., ${ }^{6}$ many researchs have shown that the noble metal-based catalysts have attracted extensive attention for a wide range of applications in many reactions, as well as the HDA reaction. Noble metal-based catalysts, including $\mathrm{Pt},{ }^{7} \mathrm{Pd},{ }^{8} \mathrm{Rh},{ }^{9}$ or bimetallic systems of these noble metals, show distinctly high catalytic activities towards 
naphthalene HYD, due to the efficient ability for dissociating hydrogen. However, noble metal has high cost and the presence of sulfur strongly influences their catalytic activity due to the poisoning of active sites. Recently, transition metal phosphides have attracted attention not only because they are very active in the hydrotreating reactions but also because they are much more stable than noble metals and metal carbides and nitrides in the atmosphere of $\mathrm{H}_{2} \mathrm{~S} .{ }^{10} \mathrm{~A}$ number of results have shown that $\mathrm{Ni}_{2} \mathrm{P}$ was the most active catalyst for both hydrodenitrogenation (HDN) and hydrodesulfurization (HDS) reactions over the past several years. ${ }^{\mathbf{1 1 - 1 3}}$ Oyama et al. compared HDS and HDN activity over different phosphides and found that their activity order follows $\mathrm{Fe}_{2} \mathrm{P}<\mathrm{CoP}<\mathrm{MoP}<\mathrm{WP}<\mathrm{Ni}_{2} \mathrm{P}$.

As common supports, silica, alumina, resin, active carbon, clay, and microporous zeolite have been widely used, while diffusion limitation limit their potential applications for catalysing bulky molecules. ${ }^{\mathbf{1 4}}$ Diffusion and catalytic tests have also proved that mesoporous zeolite, especially MCM-41, can overcome the mass transfer limitation and exhibit excellent catalytic properties for the conversion of bulky molecules..$^{15,16}$ However, purely siliceous mesoporous materials are electrically neutral frameworks, no acidity was formed on their surface. Recent studies have been proved that the supports with suitable acidity, such as $\mathrm{SiO}_{2}-\mathrm{Al}_{2} \mathrm{O}_{3},{ }^{17} \mathrm{USY},{ }^{18}$ SAPO- $11,{ }^{19} \mathrm{H}-\mathrm{ZSM}-5,{ }^{20}$ mordenites, ${ }^{21} \mathrm{H}$-beta zeolite, ${ }^{22}$ etc., have positive effects on the HDA activity. These effects have been attributed to the synergistic effects between acid sites and transition metal phosphides particles. Firstly, it was claimed that electron-deficient metal particles $\left(\mathrm{M}^{\delta+}\right)$ were formed in a transition metal phosphide/ zeolite bifunctional catalyst due to the partial electron transfer from the active particles to acidic sites of the zeolite supports. Secondly, $\mathrm{Ni}_{2} \mathrm{P}$ behaves somewhat like hydrogenase. $\mathrm{A}$ spillover based HYD pathway in which aromatic hydrocarbons were adsorbed on acidic sites and hydrogenated by the hydrogen from active particles would occur in zeolite supported catalyst. Namely, the acid sites of the support provide additional active sites on which aromatic are hydrogenated by the spillover hydrogen. ${ }^{23}$ Therefore, much effort has been devoted to the enhancement of the surface acidity with the aim of using them as catalyst support or catalyst for acid-catalyzed reactions. Aluminum may be incorporated into the mesoporous structure by adding an aluminum source to the synthesis mixture. The substitution of silicon by aluminum usually unbalances the neutral structure of silica, which may generate acid sites. The nature and strength of such acid sites, as well as the amount of trivalent cation added, may have an impact on the catalytic and adsorption properties of these materials and suit them for applications in several processes. ${ }^{24}$ Introduction of foreign ions, for instance, aluminum ions, into the silicate framework (that means, a decrease in the $\mathrm{Si} / \mathrm{Al}$ ratio) has been proved to be an efficient route for modifying the surface acidity of Si-MCM-41 and the Lewis acidity of Si-MCM-41 could be enhanced significantly after modification with aluminum ions. The Brönsted acidity of aluminosilicates generally arises from the presence of accessible hydroxyl groups or in the form of "bridging" $\mathrm{Si}$ $(\mathrm{OH})-\mathrm{Al}$ hydroxyl groups (structural hydroxyls) associated with 4-coordination framework aluminium. ${ }^{25}$ As such a process generally demands a catalyst with high product diffusivity and selectivity for aromatics HYD, molecular sieves with high surface area as well as the pore size and acidity are potential catalyst supports. Furthermore, proper pore structure and acidity favored the dispersion of the active phases.

Although HDS and HDN reactions over transition metal phosphides have been widely studied, few publications about aromatic HDA over transition metal phosphides are found. Here in this work, we prepared the Al-M supported nickel phosphide HYD catalysts with different $\mathrm{Ni} / \mathrm{P}$ molar ratios and loadings in the precursors. The catalytic performance of the nickel phosphide catalysts and the reaction pathway of naphthalene HYD were studied in detail. Compared to Pt-Al-M, the $\mathrm{Ni}_{x} \mathrm{P}-\mathrm{Al}-\mathrm{M}$ catalyst exhibited much better HYD activity and decalin selectivity.

\section{Experimental}

\subsection{Materials}

Nickel nitrate $\left(\mathrm{Ni}\left(\mathrm{NO}_{3}\right)_{2} \cdot 6 \mathrm{H}_{2} \mathrm{O}\right)$ and ammonium dihydrogen phosphate $\left(\mathrm{NH}_{4} \mathrm{H}_{2} \mathrm{PO}_{4}, 99 \%\right)$ were purchased from Tianjin Guangfu Technology Development Co., Ltd. Chloro platinic acid $\left(\mathrm{H}_{2} \mathrm{PtCl}_{6} \cdot 6 \mathrm{H}_{2} \mathrm{O}\right.$, 99\%) was obtained from Aladdin Industrial Corporation. The supports, mesostructured hexagonal frame-work, MCM-41 and Al-M were obtained from Tianjin Chem. Sci. Ltd., China and the content of $\mathrm{Al}$ in Al-M accounts for about $5 \mathrm{wt} \%$. All of the materials were analytical grade and utilized without further purification.

\subsection{Catalyst preparation}

A series of high-performance catalysts have been synthesized by temperature-programed reduction of nickel phosphate precursors according to the following steps: [1] firstly, the support was dried at $100{ }^{\circ} \mathrm{C}$ overnight prior to use. The oxide precursor was prepared by incipient wetness impregnating $\mathrm{Al}-\mathrm{M}$ with a mixture aqueous solution of $\mathrm{Ni}\left(\mathrm{NO}_{3}\right)_{2} \cdot 6 \mathrm{H}_{2} \mathrm{O}$ and $\mathrm{NH}_{4} \mathrm{H}_{2} \mathrm{PO}_{4}$, followed by drying at $80^{\circ} \mathrm{C}$ for $12 \mathrm{~h}$, and calcination at $500{ }^{\circ} \mathrm{C}$ for $2 \mathrm{~h}$ in air; [2] the oxide precursor was reduced at $650{ }^{\circ} \mathrm{C}$ for $2 \mathrm{~h}$

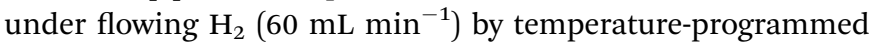
reduction (TPR) to obtain the active nickel phosphide catalyst. Finally, the product was cooled to ambient temperature under flowing $\mathrm{H}_{2}$ and was passivated for $1 \mathrm{~h}$ under flowing $1 \% \mathrm{O}_{2} / \mathrm{N}_{2}$. In one series, the loadings on the Al-M was chosen to be 10, 15, 20,25 , and $30 \mathrm{wt} \%$ with $\mathrm{Ni} / \mathrm{P}$ molar ratio of 1.25 . In another series, the Ni/P molar ratios of the precursors were $0.5,1,1.25$, $1.5,2$, and 3 with a $15 \mathrm{wt} \%$ loading.

In addition, fixing the initial $\mathrm{Ni} / \mathrm{P}$ atomic molar to 1.25 , various supports supported nickel phosphide catalysts with nickel loading of $15 \mathrm{wt} \%$ was also prepared following the same procedure. For comparison purposes, Ni-Al-M catalyst with $\mathrm{Ni}$ loading of $15 \mathrm{wt} \%$ was prepared by a procedure similar to that of the supported nickel phosphides except for the addition of the ammonium dihydrogen phosphate. Catalysts are designated according to the loading $(\mathrm{M})$ of the active phase and the $\mathrm{Ni} / \mathrm{P}$ ratio $(Y)$ as $\mathrm{M}$ wt $\% \mathrm{Ni}_{x} \mathrm{P}-\mathrm{Al}-\mathrm{M}-(\mathrm{Y})$, in which $x$ represents the actual $\mathrm{Ni} / \mathrm{P}$ values after reaction. The Pt loading in catalysts were $0.5 \mathrm{wt} \%$. 
The supported Pt catalysts were obtained through the wet coimpregnation with an appropriate amount of aqueous $\mathrm{H}_{2} \mathrm{PtCl}_{6}$ $\cdot 6 \mathrm{H}_{2} \mathrm{O}$. The impregnation lasted for $24 \mathrm{~h}$. After that, the sample was dried in air at $80^{\circ} \mathrm{C}$ for $12 \mathrm{~h}$, and finally calcined at $350{ }^{\circ} \mathrm{C}$ for $2 \mathrm{~h}$ in air. At last the catalyst was cooled to ambient temperature and washed in deionized water for twice followed by drying at $80{ }^{\circ} \mathrm{C}$ for $12 \mathrm{~h}$. In this way, Pt supported on Al-M was prepared and denoted as $0.5 \mathrm{wt} \% \mathrm{Pt}-\mathrm{Al}-\mathrm{M}$, which was used as a reference.

\subsection{Catalyst characterizations}

The catalysts were studied by a series of characterizations as follows:

Powder X-ray diffraction patterns (XRD) were recorded by a Bruker $\mathrm{D} 8$ focus diffractometer using a $\mathrm{Cu}-\mathrm{K} \alpha$ radiation. The measurement was made in the $2 \theta$ range of $10-80^{\circ}$ at $40 \mathrm{kV}$ and 40 $\mathrm{mA}$. The size and morphology of as-obtained samples were observed by field emission scanning electron microscope (FESEM, JEOL, JSM-7500F) linked with energy-dispersive X-ray spectrometer (EDS). The samples were plated with gold before measurement to avoid the electric charge accumulation. Transmission electron microscopy (TEM) images and the HAADFSTEM mapping analysis were obtained on electron microscope (FEI Tecnai, G2 F20) with a link energy-dispersive X-ray (EDX, EDAX, TEAM) system for elemental mapping operated at an accelerating voltage of $200 \mathrm{kV}$ equipped with a field emission source. The elemental composition of the catalysts was determined by ICP-OES using an SPECTRO ARCOS ICP-OES Thermo Optical Emission Spectrometer. The specific surface area of materials was analysed using nitrogen adsorption-desorption isotherms measured at $77 \mathrm{~K}$ on a BELSORP Mini instrument with preprocessing the samples in vacuum at $150{ }^{\circ} \mathrm{C}$ for $12 \mathrm{~h}$. The specific surface area data and the pore size distribution analysis were calculated by Brunauer-Emmett-Teller (BET) and nonlocal density functional theory (NLDFT) method from adsorption isotherm, respectively. Temperature-programmed desorption (TPD) experiments were performed with a Micromeritics Chemisorb 2750 instrument. All samples were pretreated in $\mathrm{N}_{2}$ at $300{ }^{\circ} \mathrm{C}$ for $2 \mathrm{~h}$ with a flow rate of $25 \mathrm{~mL} \mathrm{~min}^{-1}$. The desorption step was performed from $50{ }^{\circ} \mathrm{C}$ to $800{ }^{\circ} \mathrm{C}$ with a heating rate of $10^{\circ} \mathrm{C} \mathrm{m^{-1 }}{ }^{-1}$-ray photoelectron spectroscopy (XPS) was carried out using a Kratos Axis Ultra DLD spectrometer employing a monochromatic Al K $\alpha$ X-ray source $(h \nu=1486.6 \mathrm{eV})$, hybrid (magnetic-electrostatic) optics, and a multichannel plate and delay line detector with the $\mathrm{C} 1 \mathrm{~s}$ peak at $284.6 \mathrm{eV}$ as the internal standard. All XPS spectra were recorded using an aperture slot of $300 \times 700 \mu \mathrm{m}$, survey spectra were recorded with a pass energy of $160 \mathrm{eV}$, and high resolution spectra with a pass energy of $40 \mathrm{eV}$. CO uptake was obtained on Micromeritics Chemisorb 2750 instrument using $100 \mu \mathrm{L}$ loop ring. CO chemisorption was taken at $30{ }^{\circ} \mathrm{C}$ in the flowing $\mathrm{He}\left(100 \mathrm{~mL} \mathrm{~min}^{-1}\right)$. The samples were prereduced in flowing $\mathrm{H}_{2}$ at corresponding temperature for $1 \mathrm{~h}$.

\subsection{Catalytic activity evaluation}

Naphthalene was used to investigate the catalysts HYD performance. HDA reaction was carried out in a continuous flow fixedbed reactor equipped with a high-pressure pump.
The reaction procedure was stated in detail here. The catalysts were pelleted, crushed, and a particle size fraction of 20-40 mesh was used for the test. And catalysts were diluted with quartz sand before loaded into the reaction tube. Before reaction, the catalysts were reduced at the same temperature as preparation for $1 \mathrm{~h}$ in flowing $\mathrm{H}_{2}$. After prereduction, the system was adjusted to the desired reaction temperature $\left(250{ }^{\circ} \mathrm{C}\right)$ and pressure (3.0 $\mathrm{MPa})$. The feedstock containing naphthalene in cyclohexane ( $5 \mathrm{wt} \%$ ) was continuously pumped into the reactor at the rate of $0.17 \mathrm{~mL} \mathrm{~min}^{-1}$. The weight hourly space velocity (WHSV) was equal to $1 \mathrm{~h}^{-1}$, and the $\mathrm{H}_{2}$ /oil ratio was kept at 500 (v/v).

Liquid products were collected every hour in all assays. The reactant and products were analysed using a gas chromatograph (Agilent 7890A), equipped with a HP-5 capillary column and a flame ionization detector (FID). Products compositions were identified by GC-MS (Agilent 7890A-5977C). The HYD performance of catalysts was determined by the naphthalene conversion and product selectivity.

For TOF calculation, we used the same definition of TOF like other works do, which is moles of reactant converted divided by moles of active site. As follows, the TOF was calculated using eqn (1):

$$
\mathrm{TOF}=\frac{F_{\mathrm{A} 0}}{W} \frac{X_{\mathrm{A}}}{\mathrm{CO}_{\text {uptake }}}
$$

where $F_{\mathrm{A} 0}$ is the molar rate of reactant fed into the reactor $(\mu \mathrm{mol}$ $\left.\mathrm{s}^{-1}\right), W$ is the catalyst weight $(\mathrm{g}), \mathrm{CO}_{\text {uptake }}$ is the uptake of chemisorbed CO $\left(\mu \mathrm{mol} \mathrm{g}{ }^{-1}\right)$, and $X_{\mathrm{A}}$ is the reactant conversion (\%). $F_{\mathrm{A} 0} \cdot X_{\mathrm{A}}$ represents the moles of reactant converted per second $\left(\mu \mathrm{mol} \mathrm{s}{ }^{-1}\right)$, and $W \cdot \mathrm{CO}_{\text {uptake }}$ represents the moles of active site $(\mu \mathrm{mol})$.

\section{Results and discussion}

\subsection{X-ray diffraction}

XRD patterns were used to identify the crystalline phases formed after reduction. In order to study the effect of surface modification on the crystal structure of supported nickel phosphide catalysts, the structures of $\mathrm{Ni}_{x} \mathrm{P}-\mathrm{Al}-\mathrm{M}$ obtained from various initial $\mathrm{Ni} / \mathrm{P}$ molar ratios at a loading of $15 \mathrm{wt} \% \mathrm{Ni}_{x} \mathrm{P}$ were determined in Fig. 1(a), as well as a $\mathrm{Ni}_{2} \mathrm{P}$ and $\mathrm{Ni}_{12} \mathrm{P}_{5}$ reference. From the Fig. 1(a), it can be easily found that a broad diffraction line located at $2 \theta=23^{\circ}$ is due to the amorphous nature of mesoporous structure for all of the catalysts. ${ }^{26}$ Interestingly, the sample prepared with initial $\mathrm{Ni} / \mathrm{P}$ ratio of $1 / 2$ shows a pure $\mathrm{Ni}_{2} \mathrm{P}$ phase and the main diffraction peaks positions clearly appear around $40.7^{\circ}, 44.6^{\circ}, 47.4^{\circ}, 54.2^{\circ}$, and $54.8^{\circ}$, which correspond to the (111), (201), (210), (300), and (211) crystal faces of $\mathrm{Ni}_{2} \mathrm{P}$ (PDF\# 65-1989), respectively. In particular, when initial Ni/P ratio exceeds $1 / 1$ and further increase, the peak of the $\mathrm{Ni}_{2} \mathrm{P}$ phase declined and the $\mathrm{Ni}_{12} \mathrm{P}_{5}$ phase emerged. Diffraction peaks associated with $\mathrm{Ni}_{12} \mathrm{P}_{5}$ at $2 \theta=38.3^{\circ}, 41.7^{\circ}, 46.7^{\circ}$, and $48.9^{\circ}$ (PDF\# 22-1190) were observed in addition to those of $\mathrm{Ni}_{2} \mathrm{P}$. Namely, with increasing $\mathrm{Ni} / \mathrm{P}$ molar ratio, the excess of $\mathrm{P}$ decreases, the conditions for formation of the $\mathrm{Ni}_{2} \mathrm{P}$ phase become less favorable, so the intensities of the $\mathrm{Ni}_{2} \mathrm{P}$ diffraction 

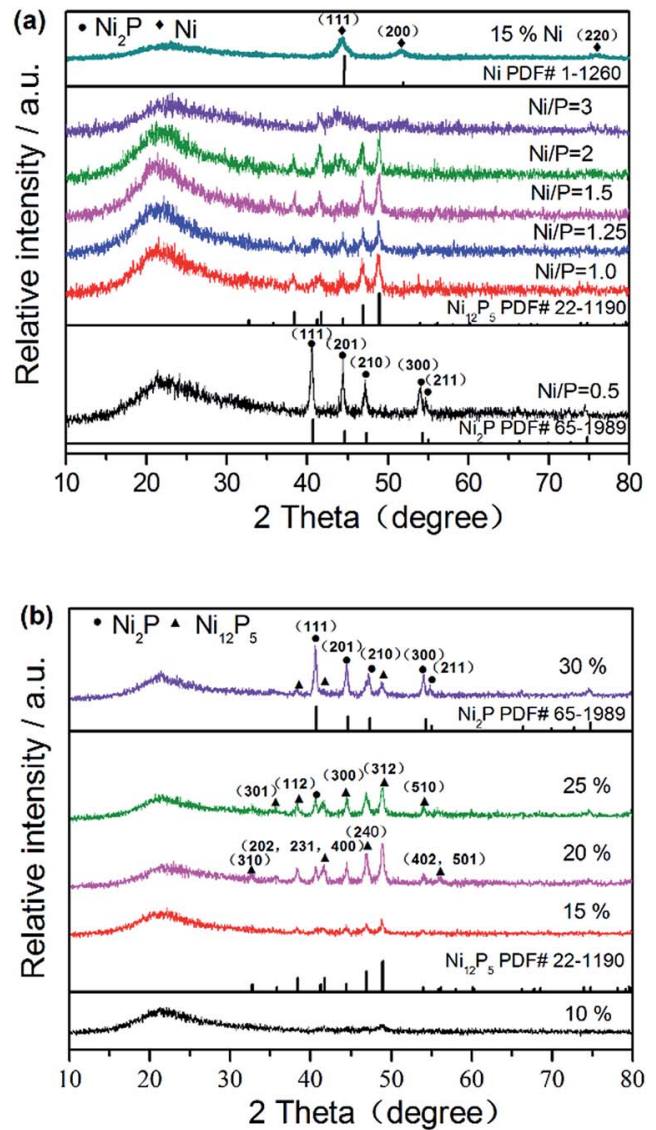

Fig. 1 XRD patterns of (a) $15 \mathrm{wt} \% \mathrm{Ni}_{X} \mathrm{P}-\mathrm{Al}-\mathrm{M}$ obtained from various initial Ni/P molar ratios and (b) $\mathrm{Ni}_{x} \mathrm{P}-\mathrm{Al}-\mathrm{M}-(1.25)$ with various $\mathrm{Ni}_{x} \mathrm{P}$ loadings.

peaks decrease. As previously proposed by Oyama et al., the lower $\mathrm{P}$ content led to formation of $\mathrm{Ni}_{12} \mathrm{P}_{5}$, which is considered as the intermediate in $\mathrm{Ni}$ to $\mathrm{Ni}_{2} \mathrm{P}$. And more phosphorus was needed to form $\mathrm{Ni}_{2} \mathrm{P} .{ }^{27}$ The formation of $\mathrm{Ni}_{12} \mathrm{P}_{5}$ and $\mathrm{Ni}$ at the low $P$ content is understandable, as $\mathrm{Ni}_{12} \mathrm{P}_{5}$ contain a relatively lower proportion of $\mathrm{P}$ than $\mathrm{Ni}_{2} \mathrm{P} . \mathrm{Ni}_{2} \mathrm{P}$ is formed by the further reaction between $\mathrm{Ni}_{12} \mathrm{P}_{5}$ and phosphorus. This is the result of the partial loss of phosphorous due to the formation of volatile $\mathrm{P}$ species, such as $\mathrm{PH}_{3}$, during reducing process, leading to a decrease in the amount of $\mathrm{P}$ on the surface. Oyama et al. also found that if the Ni/P ratio of precursor is equal to the stoichiometric ratio of $\mathrm{Ni}_{2} \mathrm{P}$, not only $\mathrm{Ni}_{2} \mathrm{P}$ phase is formed, but also a P-deficient phase $\mathrm{Ni}_{12} \mathrm{P}_{5}$ was formed. Therefore, it should be noted that an amount of phosphorus above stoichiometric proportions was necessary in order to obtain the desired stoichiometry. As the $\mathrm{Ni} / \mathrm{P}$ ratio further increased, with regard to $15 \mathrm{wt} \% \mathrm{Ni}-\mathrm{Al}-\mathrm{M}$, the new diffraction peaks at $44.4^{\circ}, 51.7^{\circ}$, and $76.3^{\circ}$ assigned to (111), (200), and (220) planes of crystalline metal Ni (PDF\# 1120) were clearly observed besides those of supports. These results demonstrate that the initial $\mathrm{Ni} / \mathrm{P}$ molar ratio in the precursor has profound impact on the structure of $\mathrm{Ni}_{x} \mathrm{P}$ catalyst. Namely, different $\mathrm{Ni} / \mathrm{P}$ ratios can result in different crystal phases of the catalyst and we also found that the catalyst with initial Ni/P ratio of about $1 / 2$ had not an excellent activity. At excessive $\mathrm{P}$ content, the active nickel phosphide surface covered by the excess $\mathrm{P}$. This is discussed in below. In a word, only pure $\mathrm{Ni}_{2} \mathrm{P}$ phase is observed with samples with higher $\mathrm{P}$ content, while with the sample with lower $\mathrm{P}$ content both $\mathrm{Ni}_{2} \mathrm{P}$ and $\mathrm{Ni}_{12} \mathrm{P}_{5}$ phases were observed. Furthermore, with $\mathrm{P}$ content fell to the lowest level, crystalline $\mathrm{Ni}$ formed in addition to little $\mathrm{Ni}_{12} \mathrm{P}_{5}$.

Fig. 1(b) shows the XRD patterns of $\mathrm{Ni}_{x} \mathrm{P}-\mathrm{Al}-\mathrm{M}$ with various $\mathrm{Ni}_{x} \mathrm{P}$ loadings from $10 \mathrm{wt} \%$ to $30 \mathrm{wt} \%$ at an initial $\mathrm{Ni} / \mathrm{P}$ molar ratio of 1.25. As shown in Fig. 1(b), X-ray line-broadening analysis of the samples indicated a weak trend toward larger crystallite sizes with increasing sample loading. As will be seen, when the $\mathrm{Ni}_{x} \mathrm{P}$ loading reached 10 wt $\%$, no prominent $\mathrm{Ni}_{x} \mathrm{P}$ diffraction peak was found compared with the other samples due to the low loading and high distribution of $\mathrm{Ni}_{x} \mathrm{P}$ on the support. So it was found that a low loading sample was particularly difficult to prepare with the right stoichiometry. This may represent a limitation for the preparation of samples consisting of compounds from two elements like nickel phosphide. As the $\mathrm{Ni}_{x} \mathrm{P}$ loading increased from $15 \mathrm{wt} \%$ to $20 \mathrm{wt} \%$, a $\mathrm{Ni}_{12} \mathrm{P}_{5}$ peak emerged and the intensity of the $\mathrm{Ni}_{12} \mathrm{P}_{5}$ diffraction peaks strengthened, finally reached the highest at $20 \mathrm{wt} \%$. With further increase in the $\mathrm{Ni}_{x} \mathrm{P}$ loading, the diffraction peak of $\mathrm{Ni}_{12} \mathrm{P}_{5}$ obviously decreased. Interestingly, when the $\mathrm{Ni}_{x} \mathrm{P}$ loading reached $30 \mathrm{wt} \%$, mainly $\mathrm{Ni}_{2} \mathrm{P}$ diffraction peaks were observed and the $\mathrm{Ni}_{12} \mathrm{P}_{5}$ diffraction peaks nearly disappeared. Moreover, excess loading leads to larger particle sizes of $\mathrm{Ni}_{x} \mathrm{P}$ and correspondingly decreases the activity. The HDA activities of the $\mathrm{Ni}_{x} \mathrm{P}-\mathrm{Al}-\mathrm{M}$ catalysts were strongly dependent on the types and dispersion of the nickel phosphide. In this study, the formation of $\mathrm{Ni}_{x} \mathrm{P}\left(\mathrm{Ni}_{2} \mathrm{P}\right.$ and/or $\left.\mathrm{Ni}_{12} \mathrm{P}_{5}\right)$ on the surface of Al-M could be decided by controlling the loading. And it was found that catalysts of intermediate loading had high activity, as shown in below. Besides, low-angle powder X-ray diffraction patterns of the samples are depicted in Fig. S1. $\dagger$ Only the most intense characteristic peak of MCM-41 structure can be observed for $0.5 \mathrm{wt} \% \mathrm{Pt}-\mathrm{Al}-\mathrm{M}$ apart from supports. This fact indicates that the structural order of MCM-41 decreases for the supported catalysts, very likely due to the uneven distribution of active phase particles inside the pores. Meanwhile, the wideangle XRD patterns of Al-M support along with the corresponding Pt-loaded catalyst are displayed in Fig. S2. $\dagger$ For 0.5 wt\% Pt-Al-M, diffraction peaks of platinum are hardly visible probably owing to the low content. Crystallite size of various catalysts also have evaluated based on Scherrer equation. The corresponding results are listed in last column of Table S1. $\dagger$ In practical terms, the crystallite sizes of samples are in close agreement with the results of particle size distribution according to TEM images, as described in Fig. 3 below.

\subsection{SEM}

To further confirm the composition of the catalysts and the effective loading of the $\mathrm{Ni}_{x} \mathrm{P}$ in the materials. Fig. 2 shows the SEM and EDS mapping images of different catalysts (red dot is nickel atom and yellow dot is phosphorus). Fig. 2(a), (b) and (d) show that the Ni-Al-M has better metal dispersion than the 

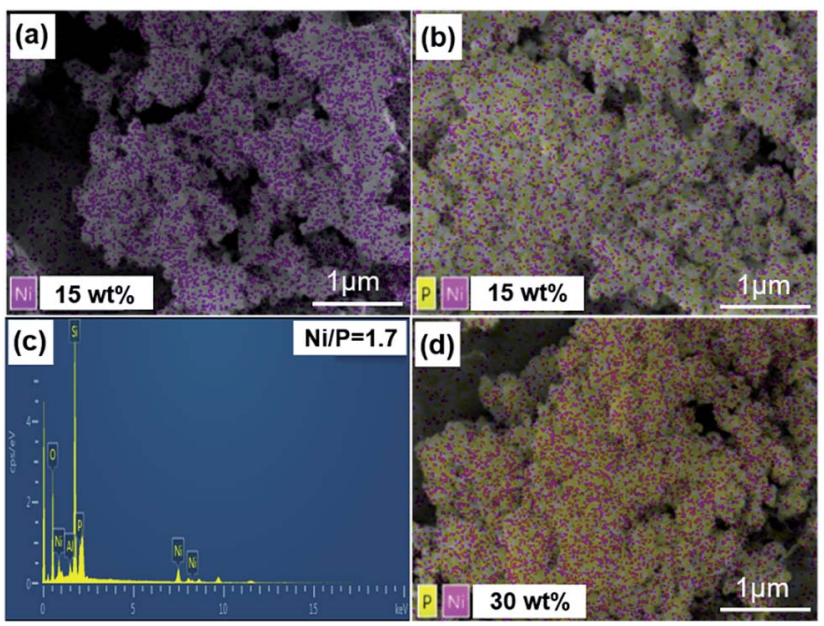

Fig. 2 The SEM and EDS mapping images of different catalysts (red dot refer to nickel atom, and yellow dot refer to phosphorus atom), (a) 15 wt\% Ni-Al-M, (b) 15 wt\% Ni $x_{x} \mathrm{P}-\mathrm{Al}-\mathrm{M}-(1.25)$, (c) $15 \mathrm{wt} \% \mathrm{Ni} x_{x} \mathrm{P}-\mathrm{Al}-\mathrm{M}-$ (1.25), and (d) $30 \mathrm{wt} \% \mathrm{Ni}_{x} \mathrm{P}-\mathrm{Al}-\mathrm{M}-(1.25)$.

$\mathrm{Ni}_{x} \mathrm{P}-\mathrm{Al}-\mathrm{M}$. Moreover, the distribution of $\mathrm{Ni}_{x} \mathrm{P}$ particle is relatively uniform, no obvious sintering and aggregation was observed. Compared to Fig. 2(b) and (d) show that Ni and $\mathrm{P}$ dispersion decreased significantly with the increase in $\mathrm{Ni}_{x} \mathrm{P}$ loading of the same Ni loading. Fig. 2(c) gives the mole ratio of $\mathrm{Ni} / \mathrm{P}=1.71$ measured by EDS. Considering that EDS is a semiquantitative analysis method, and there may be due to a partial loss of the phosphorus during preparation, the mole ratio of $\mathrm{Ni}$ / $\mathrm{P}=1.71$ is a reasonable value. In addition, previous work had shown that phosphorus is removed as $\mathrm{PH}_{3}$ during the reduction procedure and that some $\mathrm{P}$ was left on the better dispersed supported $\mathrm{Ni}_{2} \mathrm{P}$ catalysts, even though higher temperatures were applied for reducing these well dispersed samples. ${ }^{28}$ This again is consistent with stronger interactions between $\mathrm{Ni}$ and $\mathrm{P}$ in the smaller crystallites. In addition, Fig. S3† shows the SEM, mapping image (cyan dot refer to platinum atom), and EDS of 0.5 wt $\%$ Pt-Al-M catalyst. This study reveals that small Pt particles with a rather homogeneous size distribution are welldispersed on the Al-M, as shown in Fig. S3. $\dagger$ Besides, the amount of the platinum is $0.46 \mathrm{wt} \%$ measured by EDS.

\subsection{TEM}

Fig. 3 shows the representative TEM images of $\mathrm{Ni}_{x} \mathrm{P}-\mathrm{Al}-\mathrm{M}$ catalysts synthesized at $650{ }^{\circ} \mathrm{C}$ from $\mathrm{Ni}\left(\mathrm{NO}_{3}\right)_{2} \cdot 6 \mathrm{H}_{2} \mathrm{O}$ and $\mathrm{NH}_{4} \mathrm{H}_{2} \mathrm{PO}_{4}$ precursors with a mole ratio of $\mathrm{Ni} / \mathrm{P}=1.25$, and with different loadings: (a) $10 \mathrm{wt} \%$, (b) $15 \mathrm{wt} \%$, (c) $20 \mathrm{wt} \%$, (d) $30 \mathrm{wt} \%$, and inset is the corresponding particle size distribution histogram. The TEM images exhibited a large number of $\mathrm{Ni}_{x} \mathrm{P}$, fairly uniform globular nanoparticles with a mean particle size of about 5-10 nm, were observed to be supported on $\mathrm{Al}-\mathrm{M}$, indicating $\mathrm{Ni}_{x} \mathrm{P}$ has good dispersion on the Al-M support. Furthermore, the results clearly show that the distributions of the nanoparticles exhibited poor dispersion and significantly aggregation, along with the increase in the $\mathrm{Ni}_{x} \mathrm{P}$ loading from 10 to $30 \mathrm{wt} \%$. Correspondingly, the particle size of nickel phosphides increased, which is similar to the
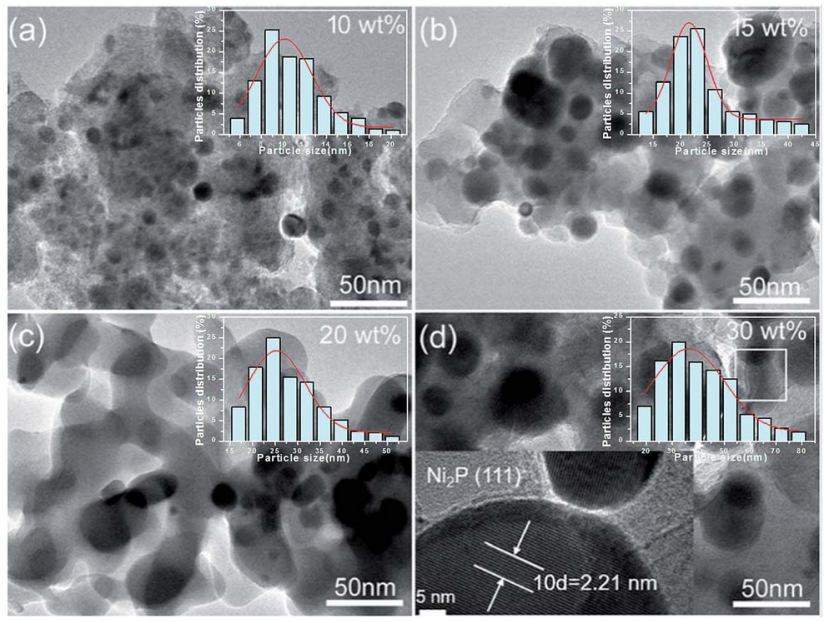

Fig. 3 The TEM images of $\mathrm{Ni}_{x} \mathrm{P}-\mathrm{Al}-\mathrm{M}$ catalysts synthesized at $650{ }^{\circ} \mathrm{C}$ from $\mathrm{Ni}\left(\mathrm{NO}_{3}\right)_{2} \cdot 6 \mathrm{H}_{2} \mathrm{O}$ and $\mathrm{NH}_{4} \mathrm{H}_{2} \mathrm{PO}_{4}$ precursors with a mole ratio of $\mathrm{Ni} / \mathrm{P}=1.25$, and with different loadings: (a) $10 \mathrm{wt} \%$, (b) $15 \mathrm{wt} \%$, (c) 20 $w t \%$, (d) $30 \mathrm{wt} \%$. Inset is the corresponding particle size distribution histogram.

XRD result using the Scherrer formula. A magnified high resolution TEM image of 15 wt $\% \mathrm{Ni}_{x} \mathrm{P}-\mathrm{Al}-\mathrm{M}$ approximately yields $d$ spacing values of $0.221 \mathrm{~nm}$, which was consistent with the $\{111\}$ crystallographic plane of $\mathrm{Ni}_{2} \mathrm{P}$, in good agreement with the calculated values (PDF\# 65-1989), as shown in Fig. 3(d). In contrast, the mapping analysis of $15 \mathrm{wt} \% \mathrm{Ni}_{x} \mathrm{P}-\mathrm{Al}-\mathrm{M}$ also further confirmed the presence and good distributions of nickel and phosphorus elements in Fig. S4. $\uparrow$ Also of note that the highest nanodispersity of the $\mathrm{Ni}_{x} \mathrm{P}$ nanoparticles was observed on the $15 \mathrm{wt} \% \mathrm{Ni}_{x} \mathrm{P}-\mathrm{Al}-\mathrm{M}$ for all catalysts. It shows a spherical shape with good dispersion of nanocrystalline $\mathrm{Ni}_{x} \mathrm{P}$ on the $\mathrm{Al}-\mathrm{M}$ support. Inset show the consequent size distribution histograms of $\mathrm{Ni}_{x} \mathrm{P}$-based catalysts. The micrographs obtained for each catalyst were analyzed to determine the average particle diameter and size distribution of the $\mathrm{Ni}_{x} \mathrm{P}$ nanoparticles. A measurement of at least 200 nanoparticles, assuming virtually spherical and randomly orientated particles was taken for the construction of the size distribution histograms. The $\mathrm{Ni}_{x} \mathrm{P}$ nanoparticles are homogeneously distributed over the supports. The sizes of the $\mathrm{Ni}_{x} \mathrm{P}$ nanoparticles for all the catalysts are about in the range of 5-80 $\mathrm{nm}$.

\subsection{ICP-OES}

The composition of the catalysts is further measured by ICPOES and the results were summarized in Table S2.† Obviously, as seen in Table $\mathrm{S} 2, \dagger$ it is clearly indicated that the experimental values were much larger than theoretical values of $\mathrm{Ni} / \mathrm{P}$ molar ratio. It might be due to the extra phosphorous except volatilized as $\mathrm{PH}_{3}$ and residual $\mathrm{PO}_{x}{ }^{n-}$ species during the reduction process, partly situated in the surface of the catalyst, which is further explained in detail below.

\section{5 $\mathrm{N}_{2}$ sorption-desorption experiment}

Fig. S5 $\uparrow$ shows the $\mathrm{N}_{2}$ adsorption-desorption isotherms of (a) 15 wt $\% \mathrm{Ni}_{x} \mathrm{P}-\mathrm{Al}-\mathrm{M}$ with various $\mathrm{Ni} / \mathrm{P}$ molar ratios, (b) $\mathrm{Ni}_{x} \mathrm{P}-\mathrm{Al}-\mathrm{M}-$ (1.25) with different $\mathrm{Ni}_{x} \mathrm{P}$ loadings, (c) MCM-41, Al-M, 
physically mixed MCM-41 $+\gamma-\mathrm{Al}_{2} \mathrm{O}_{3}$, denoted as $(\mathrm{M}+\mathrm{Al})$ supports, and $0.5 \mathrm{wt} \% \mathrm{Pt}-\mathrm{Al}-\mathrm{M}(\mathrm{d})$ the corresponding $\mathrm{BJH}$ pore size distributions of supports and $0.5 \mathrm{wt} \% \mathrm{Pt}-\mathrm{Al}-\mathrm{M}$ catalyst. As can be seen from Fig. S5(a)-(c), $\dagger$ all the samples of $\mathrm{N}_{2}$ isotherms are basically identical to pure supports. The samples present a reversible adsorption-desorption type IV isotherm characteristic with a hysteresis loop according to the IUPAC classification, showing the presence of some mesopores. ${ }^{29}$ This type of hysteresis corresponds to aggregates or agglomerates of particles which form pores in the form of cleft such as plates or sharp particles such as buckets, with uniform distribution. As for Al-M and $(\mathrm{M}+\mathrm{Al})$ supports, it was very similar to that of the pure MCM-41, the adsorption and desorption lines were almost overlapped, nearly leading to no hysteresis loop formation. The coincidence of the adsorption and desorption lines could be ascribed to a similar mechanism for the two processes, which reflects the absence of adsorbate pore blocking. The absence of a hysteresis loop and the sharp curvature along the second stage, suggest the existence of uniform and cylindrical channels throughout the materials. The pore size distributions obtained by $\mathrm{BJH}$ analysis of these curves show no marked differences among the samples as we can see from Fig. S5(d). $\dagger$ Pore distribution for all of the samples was mono-modal showing that they belong to the mesoporous materials. The pore diameters for all samples were almost same to original MCM-41, suggesting that $\mathrm{Ni}_{x} \mathrm{P}$ particles were basically limited on the external surface of the mesoporous support and only some of the MCM-41 was destroyed after $\mathrm{Ni}_{x} \mathrm{P}$ loading. In addition, the corresponding textural characterization of the supports and catalysts are presented in Table $\mathrm{S} 1 . \dagger$ The BET specific surface area and pore volume of the MCM-41 were $893 \mathrm{~m}^{2} \mathrm{~g}^{-1}$ and 0.96 $\mathrm{cm}^{3} \mathrm{~g}^{-1}$, respectively. However, the incorporation of alumina in the MCM-41 matrix resulted in a slight decrease on the surface area and the pore volume, which can be attributed to the stability of the siliceous material and also a decrease in the pore volume due to the blockage of some from pores of the MCM41. ${ }^{30}$ The date also indicated that the deposition of $\mathrm{Ni}_{x} \mathrm{P}$ and $\mathrm{Pt}$ on the support surface causes a greater drop in the surface area and pore volume. Meanwhile, both the BET surface areas and pore volumes of the samples varied from high to low, with corresponding $\mathrm{Ni}_{x} \mathrm{P}$ loadings increasing from 10 to 20 and 30 $\mathrm{wt} \%$. One reason is that active component loadings increased the catalyst density so that the proportion of Al-M in the total quality of catalysts correspondingly decreased. The other is that a number of pores of the supports were blocked/filled by $\mathrm{Ni}_{x} \mathrm{P}$ during the catalyst preparation. However, no significantly change in the pore diameter is observed from catalysts compared to their corresponding samples, indicating that no additional $\mathrm{P}$ is deposited on the walls of the pores.

\section{$3.6 \quad \mathrm{NH}_{3}-\mathrm{TPD}$}

$\mathrm{NH}_{3}$-TPD was performed to elucidate the relationship between the catalysts activity and types of acidic sites on the catalysts. Fig. 4 shows the $\mathrm{NH}_{3}$-TPD profiles of the MCM-41, Al-M supports, and the supported $\mathrm{Ni}_{x} \mathrm{P}$ catalysts with different $\mathrm{Ni} / \mathrm{P}$ molar ratios. In a typical $\mathrm{NH}_{3}-\mathrm{TPD}$ profile, peaks are generally

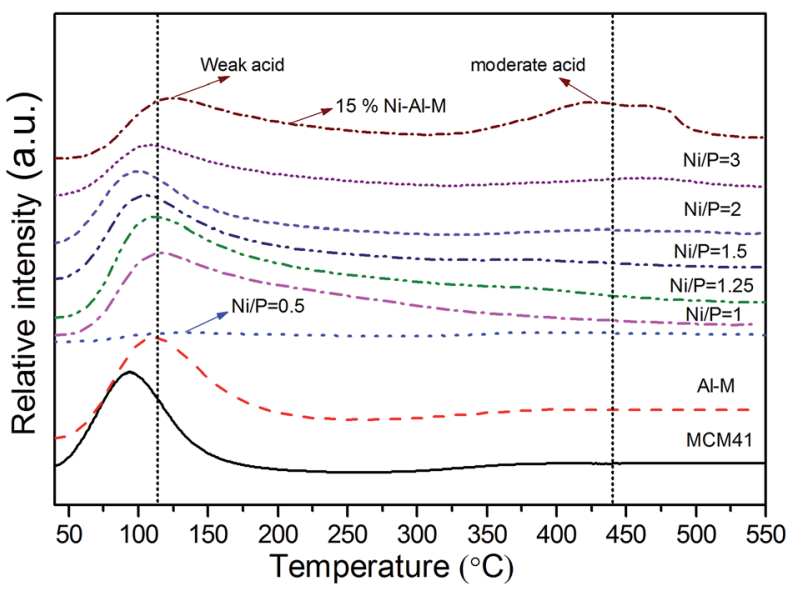

Fig. $4 \mathrm{NH}_{3}$-TPD profiles of the MCM-41, Al-M supports, and the supported $\mathrm{Ni}_{X} \mathrm{P}$ catalysts with different $\mathrm{Ni} / \mathrm{P}$ molar ratios.

observed in three temperature regions. The regions of the $T_{\max }$ (temperature maximum) from 20 to $200{ }^{\circ} \mathrm{C}, T_{\max }$ from 200 to $500{ }^{\circ} \mathrm{C}$, and $T_{\max }$ higher than $500{ }^{\circ} \mathrm{C}$ are referred to as lowtemperature, moderate-temperature and high-temperature regions, corresponding to weak acidic sites, intermediate acidic sites, and strong acidic sites, respectively..$^{31}$ The principal objective of this work is to increase the stability as well as the acidity of the support by adding alumina, which play a vital role in the HDA and product selectivity during hydrotreating. Generally, MCM41 support presented the lowest amount of acid sites. As expected, the addition alumina to the MCM-41 supports, the surface acidity increases with decreasing the $\mathrm{Si}$ / Al molar ratio. Desorption peak around low-temperature was assigned to Lewis and Brönsted acid sites of weak acidic strength, while desorption peak about high-temperature was assigned to intermediate Brönsted acid sites (usually bridging $\mathrm{Si}-(\mathrm{OH})-\mathrm{Al}$ groups $).^{32-34}$ It is demonstrated that there are the weak and medium strength Brönsted acid sites on Al-M, which correspond to the $\mathrm{NH}_{3}$ desorptions with the peaks at about 120 and $400{ }^{\circ} \mathrm{C}$, respectively, as shown in Fig. 4. However, when Ni or $\mathrm{Ni}_{x} \mathrm{P}$ was supported on $\mathrm{Al}-\mathrm{M}$, it is composed of two types of weak acid sites, Lewis and Brönsted, which are ascribed to the electron-deficient $\mathrm{Ni}$ site and to the $\mathrm{P}-\mathrm{OH}, \mathrm{Si}(\mathrm{OH}) \mathrm{Al}$ group, respectively. Since the electron-deficiency of these nickel ions is very high and nickel in nickel phosphide exists in positive charges ${ }^{35}$ they may play a role of Lewis sites. Also an additional amount of weak acidic sites was found with a shift of the peak to lower temperature shown in Fig. 4. The acid sites on Al-M still maintained, but some of them could be covered by $\mathrm{Ni}$ or $\mathrm{Ni}_{x} \mathrm{P}$ particles. Besides, as indicated in Fig. 4, Ni-Al-M had more medium strength Brönsted acid sites but less weak strength acid sites than $\mathrm{Ni}_{x} \mathrm{P}-\mathrm{Al}-\mathrm{M}$. In other words, there is less medium strength Brönsted acid sites on $\mathrm{Ni}_{x} \mathrm{P}-\mathrm{Al}-\mathrm{M}$, which is due to the coverage of acid sites with $\mathrm{P}$. The amount and strength of acid sites are related not only to the activity of naphthalene HYD but also to the extent of concomitant further cracking and coke disposition. Meanwhile, the total acidity amounts are listed in Table S4. $\uparrow$ Moreover, $\mathrm{NH}_{3}$-TPD profiles for supports MCM-41, 
physically mixed $\mathrm{M}+\mathrm{Al}$, Al-M supports, and $0.5 \mathrm{wt} \% \mathrm{Pt}-\mathrm{Al}-\mathrm{M}$ catalyst are depicted in Fig. S6. $\dagger$ In general, these profiles for Pt-based catalyst consist of two peaks. One appears at a low temperature range of around $150-200{ }^{\circ} \mathrm{C}$ while the other appears at a high temperature range of around $350-450{ }^{\circ} \mathrm{C}$. The low and high temperature peaks correspond to the weak and strong acid sites, respectively. ${ }^{36}$ In this study, as shown in Fig. S6, $\dagger$ after the addition of Pt, two patterns for $\mathrm{NH}_{3}$ desorption appeared. The first curve was due to the $\mathrm{NH}_{3}$ adsorption on pure mesoporous surface. The second curves were due to the $\mathrm{NH}_{3}$ adsorption on the impregnated $\mathrm{Pt}$ species on Al-M. ${ }^{36}$ Obviously, the $\mathrm{NH}_{3}$ desorption peak temperatures and areas increase, which illustrates that the addition of Pt can effectively enlarge the number and strength of acid sites over $0.5 \mathrm{wt} \% \mathrm{Pt}-$ Al-M catalyst. In particular, the $\mathrm{NH}_{3}$ amounts desorbed at low temperature reached about 3 times in $0.5 \mathrm{wt} \%$ Pt-Al-M compared with pure Al-M.

\subsection{XPS}

In order to gain further insight into the surface composition of surface oxidation layer and the valence states of active components, the XPS of catalysts was performed. The XPS Ni $2 \mathrm{p}$ and $\mathrm{P}$ 2p spectra of $15 \mathrm{wt} \% \mathrm{Ni}_{x} \mathrm{P}-\mathrm{Al}-\mathrm{M}-(1.25)$ catalyst are presented in Fig. 5(a) and (b). All the spectra were decomposed by fitting using Origin Pro. 8.5, in which the black lines represent the experimental data, the red lines are the envelopes of decomposed features and the other lines are the Gaussian components peaks, as shown in Fig. 5. According to the result in Fig. 5(a), we can see that the Ni 2p core level spectrum involves two contributions, which correspond to the spin-orbital splitting of the $\mathrm{Ni}$ $2 \mathrm{p}_{3 / 2}$ and $\mathrm{Ni} 2 \mathrm{p}_{1 / 2}$ lines (about $17 \mathrm{eV}$ ), respectively. Ni $2 \mathrm{p}_{3 / 2}$ corelevel spectrum consists of three components, the first of which centered at $851.6-853.5 \mathrm{eV}$ can be assigned to reduced $\mathrm{Ni}^{\delta+}$ species in the $\mathrm{Ni}_{x} \mathrm{P}$ phase, and the second is at $856.3-857.6 \mathrm{eV}$, corresponding to $\mathrm{Ni}^{2+}$ ions interacting possibly with phosphate ions as a consequence of a superficial passivation, ${ }^{37}$ along with the broad satellite peak at approximately $6.0 \mathrm{eV}$ higher than that of the $\mathrm{Ni}^{2+}$ species, and this shake-up peak is ascribed to divalent species. This observation is consistent with that of Korányi et $a l .{ }^{38}$ Other broad peaks on the high binding energy side can be assigned to the $\mathrm{Ni} 2 \mathrm{p}_{1 / 2}$ components. The $\mathrm{P} 2 \mathrm{p}$ binding energy spectrum features a low intensity peak at $129.5 \mathrm{eV}$ due to $\mathrm{P}^{\delta-}$ of the reduced metal phosphides and a peak at $134.5 \mathrm{eV}$ due to surface metal phosphate species in $\mathrm{PO}_{4}{ }^{3-}$ arising from the superficial oxidation of the nickel phosphide particles. The result is similar to other report. ${ }^{39}$ Generally, the higher binding energy indicates a lower electron density. The Ni $2 p$ binding energies in $\mathrm{Ni}_{x} \mathrm{P}$ phase are much higher than reported values for Ni metal (852.5-852.9 eV) and lower than those reported for $\mathrm{Ni}$ in $\mathrm{NiO}(854.1 \mathrm{eV}),{ }^{40}$ which is influenced by the formation of the greater interaction with the support, indicating that the $\mathrm{Ni}$ in $\mathrm{Ni}_{x} \mathrm{P}$ carries a partial positive charge $\left(\delta^{+}\right)$, where $0<\delta<2$, whereas the $\mathrm{P} 2 \mathrm{p}$ binding energies are below the value reported for elemental phosphorus $(130.2 \mathrm{eV})$, revealing the small transfer of electron from $\mathrm{Ni}$ to $\mathrm{P}$ in nickel phosphide and a partial negative charge $\left(\delta^{-}\right)$carried on P surface, where $0<\delta<$
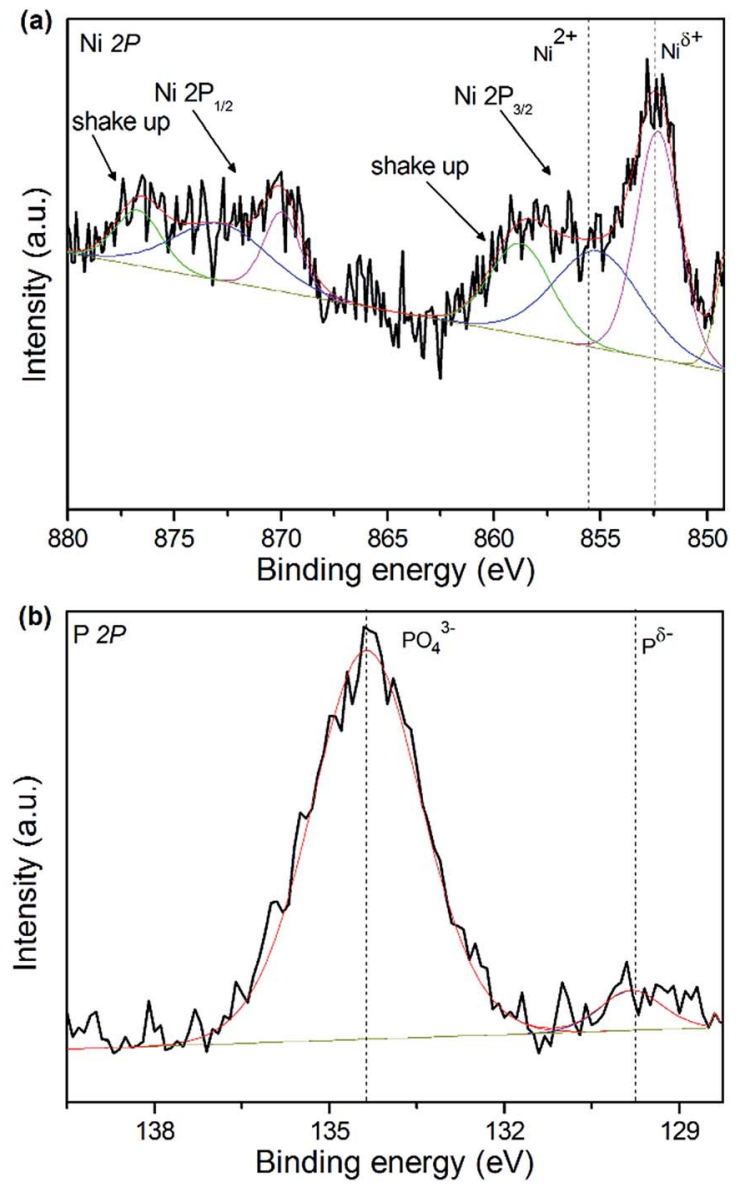

Fig. 5 XPS spectra in the $\mathrm{Ni} 2 \mathrm{p}$ and $\mathrm{P} 2 \mathrm{p}$ regions for $15 \mathrm{wt} \% \mathrm{Ni}_{x} \mathrm{P}-\mathrm{Al}-$ $M-(1.25)$ catalyst: (a) Ni $2 p$ core level spectra and (b) P $2 p$ core level spectra.

$1{ }^{40}$ Moreover, an active site with a high electron density favors the formation of a $\pi$ back bond between the aromatic ring and active sites, which promotes the HYD of the aromatic ring. Accordingly, XPS analyses are also used to calculate the surface $\mathrm{Ni} / \mathrm{P}$ atomic ratios as well as surface compositions of the catalysts before their use. The XPS analysis results for $15 \mathrm{wt} \% \mathrm{Ni}_{x} \mathrm{P}-$ MCM-41-(1.25) and $15 \mathrm{wt} \% \mathrm{Ni}_{x} \mathrm{P}-\mathrm{Al}-\mathrm{M}-(1.25)$ catalysts, given in Table S3. $\dagger$ It can be seen that as prepared catalysts exhibited lower contents values of $\mathrm{Ni}, \mathrm{P}$ and the surface $\mathrm{Ni} / \mathrm{P}$ ratios determined using XPS are far below the theoretical Ni/P ratio corresponding to the precursors, which shows that surplus phosphorous tend to distribute on the surface of the catalysts.

\subsection{Hydrogenation activity}

Previous studies have shown that the activity of aromatic HYD depended not only on the amounts of accessible active sites, but also on the surface acid properties. ${ }^{41}$ Typically, the naphthalene HYD, which was a first-order reaction. There are three major products formed from naphthalene on these catalysts: transdecalin, cis-decalin and tetralin. Meanwhile, trans- and cis-decalin were integrated as decalin. $\mathrm{The}_{\mathrm{Ni}} \mathrm{P}$ loadings and $\mathrm{Ni} / \mathrm{P}$ ratio had been reported to have an important role in catalytic activity. 
To investigate the catalytic activity of $\mathrm{Ni}_{x} \mathrm{P}-\mathrm{Al}-\mathrm{M}$, the HYD of naphthalene was conducted in a fixed bed reactor at the conditions of $P=3 \mathrm{MPa}, T=250-330{ }^{\circ} \mathrm{C}$ and $\mathrm{WHSV}=1 \mathrm{~h}^{-1}$. Fig. 6(a) shows the influence of $\mathrm{Ni}_{x} \mathrm{P}$ loadings on HDA activity and selectivity for naphthalene over $\mathrm{Ni}_{x} \mathrm{P}-\mathrm{Al}-\mathrm{M}$ catalysts at a $\mathrm{Ni}$ / $P$ ratio of 1.25 after $6 \mathrm{~h}$ on-stream. As depicted in Fig. 6(a), it could be observed that all catalysts showed high naphthalene conversion. With the increasing of the loading, the catalytic activity and selectivity first increases and then decreases. Accordingly, samples with low loadings showed low selectivity to decalin. When the $\mathrm{Ni}_{x} \mathrm{P}$ loading was $10 \mathrm{wt} \%$, the selectivity to decalin was only $44.7 \%$, and when the loadings reached $20 \mathrm{wt} \%$ and $25 \mathrm{wt} \%$, the selectivity to decalin were $98.0 \%$ and $95.9 \%$, respectively. But further increasing of loading led to decline of activity and selectivity. When the $\mathrm{Ni}_{x} \mathrm{P}$ loading rises to $30 \mathrm{wt} \%$, the selectivity to decalin rapidly decreased to $36.3 \%$. The HDA properties decrease as a result of the lack of catalytic activity centers, the poor $\mathrm{Ni}_{x} \mathrm{P}$ dispersion and the smaller surface area led by excessive load. Combined with the XRD, SEM, and TEM analysis, these results suggest that the loading content and dispersion both have an effect on the HDA properties. Moreover, the one with $15 \mathrm{wt} \%$ loading had went through the highest
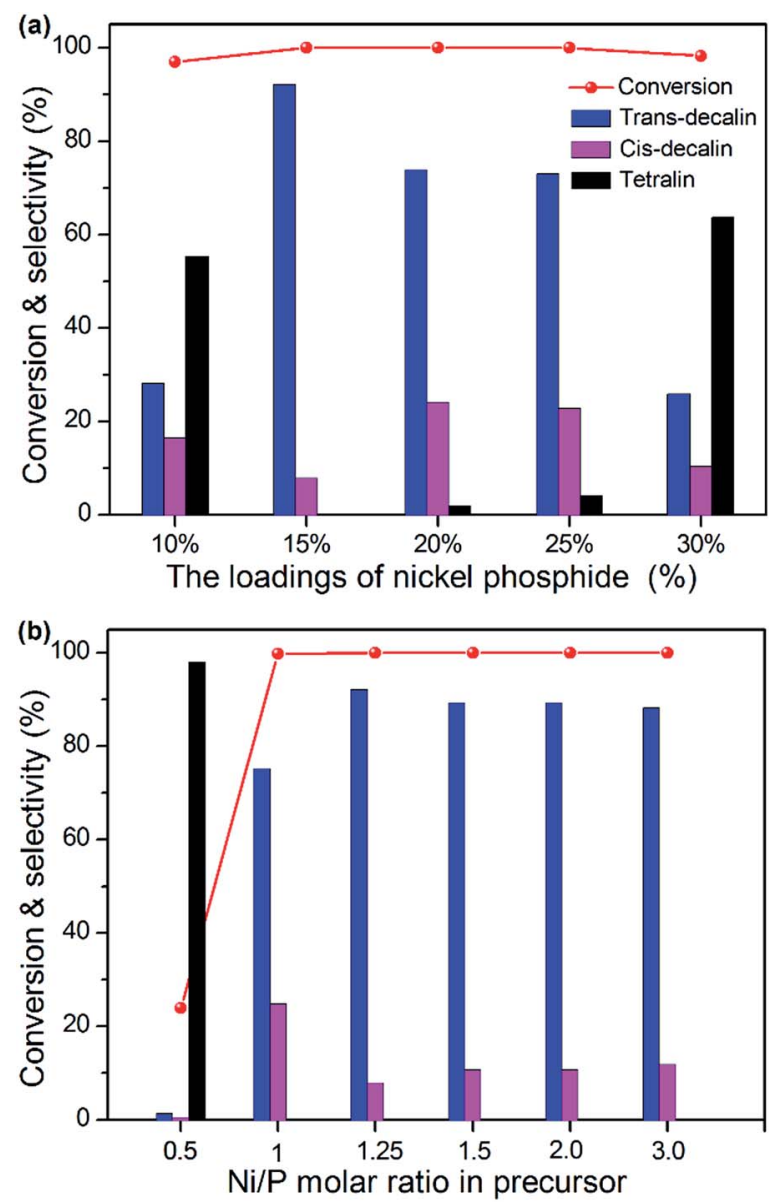

Fig. 6 Naphthalene conversion and selectivity to decalin (a) over $\mathrm{Ni}_{x} \mathrm{P}-\mathrm{Al}-\mathrm{M}$ with different $\mathrm{Ni}_{X} \mathrm{P}$ loadings and (b) over $\mathrm{Ni}_{X} \mathrm{P}-\mathrm{Al}-\mathrm{M}$ with different $\mathrm{Ni} / \mathrm{P}$ molar ratio in precursor as $0.5,1.0,1.25,1.5,2.0$, and 3.0 at $270{ }^{\circ} \mathrm{C}$ and $3 \mathrm{MPa}$. naphthalene conversion and selectivity to decalin, which were $100 \%$ and $99.9 \%$ at $270{ }^{\circ} \mathrm{C}$. Fig. S7† present HDA activity performed over the temperature range of $250-330{ }^{\circ} \mathrm{C}$. It shows the effect of temperature on the selectivity. Wherein, the decrease in selectivity to decalin with increase in reaction temperature and this appears to be common for all the catalysts, which is probably due to thermodynamic equilibriums limitations and coke formation that can hinder the access to the active sites, as it has been previously found. ${ }^{42}$ Correspondingly, the conversion toward naphthalene and the selectivity to decalin went through a maximum at about $270{ }^{\circ} \mathrm{C}$. As mentioned earlier, the sample with $\mathrm{Ni}_{x} \mathrm{P}$ loading of $15 \mathrm{wt} \%$ gave highest activity for decalin formation. Therefore, we studied the effect of initial $\mathrm{Ni} / \mathrm{P}$ ratio with the $\mathrm{Ni}_{x} \mathrm{P}$ loading of $15 \mathrm{wt} \%$ on the HYD of naphthalene. The results of HYD of naphthalene over those samples with different Ni/P molar ratios at the level of $15 \mathrm{wt} \%$ loading and a reaction temperature of $270{ }^{\circ} \mathrm{C}$ were exhibited in Fig. 6(b). As a general trend, it was obvious that the HDA activity altered with the change of the $\mathrm{Ni} / \mathrm{P}$ molar ratios and the corresponding naphthalene conversion and selectivity towards decalin first increased and then decreased with the increase of the $\mathrm{Ni} / \mathrm{P}$ molar ratio, as shown in Fig. 6(b). Much the same as above analysis, two main products are detected: decalin and tetralin. No rupture products were detected except tetralin and decalin, indicating the acidity on the $\mathrm{Ni}_{x} \mathrm{P}-\mathrm{Al}-\mathrm{M}$ sample could not catalyze the open-ring reaction of naphthalene. The product selectivity with $\mathrm{Ni} / \mathrm{P}$ ratio of $1 / 2$ mainly contained tetralin, and the decalin content is lowest, only about $2.0 \%$, and that of other samples are higher. Along with the increase of initial Ni/P ratio, and the selectivity of decalin increases dramatically. The sample with an initial Ni/P ratio of 1.25 has the highest HYD conversion and the selectivity to decalin, about $100 \%$ and $99.9 \%$, which is higher than that of the other four samples, with $\mathrm{Ni} / \mathrm{P}$ ratios of 1.0, 1.5 2.0, and 3.0. The likely reason is that, on the one hand, with lower $\mathrm{P}$ content, some P-deficient $\mathrm{Ni}_{12} \mathrm{P}_{5}$ or Ni metal phase are formed, which have been found to be less active in HYD reaction. Nevertheless, on the other hand, at higher $\mathrm{P}$ content level, the extra phosphorous partially located at the outer surface of the catalyst, ${ }^{\mathbf{4 3}}$ further covering the active sites and leading to blocking some apertures of the $\mathrm{Ni}_{x} \mathrm{P}-\mathrm{Al}-\mathrm{M}$ catalysts, as it has been previously mentioned. Moreover, it is possible affected by the relatively large crystallite size of nickel phosphide, which should reduce the number of available centers for HYD activity. Similaring to the optimal Ni/P ratio of 1.25 for the $\mathrm{SiO}_{2}$ supported Ni-P catalyst reported in the published literatures, ${ }^{44}$ our work also shows the optimal $\mathrm{Ni} / \mathrm{P}$ ratio is 1.25 . Besides, the detailed product distributions obtained with different temperature are also shown in Fig. S8. $\dagger$ It can be seen that product distributions over the six catalysts showed a similar current: the selectivity of decalin increased with reaction temperature until a plateau was noticed at around $270{ }^{\circ} \mathrm{C}$. When temperature was approximately above $300{ }^{\circ} \mathrm{C}$, concentrations of both trans-decalin and cis-decalin declined, and concentration of tetralin slightly increased. This indicates a high temperature does not promote further HYD. Fig. S9† compares the conversions and selectivities obtained from naphthalene HYD over $\mathrm{Ni}_{-}, \mathrm{Ni}_{x} \mathrm{P}-$, and Pt-supported catalysts. As 
shown in Fig. $\mathrm{S} 9, \uparrow$ the result showed that $15 \mathrm{wt} \% \mathrm{Ni}_{x} \mathrm{P}-\mathrm{Al}-\mathrm{M}$ has the highest naphthalene conversion and decalin selectivity than 15 wt\% Ni-Al-M, 15 wt\% Ni $x_{x} \mathrm{P}-\mathrm{MCM}-41,0.5$ wt $\% \mathrm{Pt}-\mathrm{Al}-\mathrm{M}$ and physical mixed $15 \mathrm{wt} \% \mathrm{Ni}_{x} \mathrm{P}-(\mathrm{M}+\mathrm{Al})$ samples, which indicates that the support plays important role and this implies again the occurrence of a synergistic effect between the support and $\mathrm{Ni}_{x} \mathrm{P}$. Combined with characterization results mentioned above, it seems that the electronic state of $\mathrm{Ni}_{x} \mathrm{P}$ surface, acid site number as well as strength, and particle size provide significant effects on the catalytic performance. The MCM-41 surface is homogeneous and had hardly any acid sites. ${ }^{45}$ The interaction between the supported $\mathrm{Ni}_{x} \mathrm{P}$ and the MCM-41 support is very weak. Some $\mathrm{Ni}_{x} \mathrm{P}$ sintering and agglomeration to large particles occurs during calcination and reduction. However, the aluminum promoters affect the acid property and the electron property as well as improving the dispersion of the $\mathrm{Ni}_{x} \mathrm{P}$ particles via isolation and anchor effects. The improvement in $\mathrm{Ni}_{x} \mathrm{P}$ dispersion, which implies more active sites, is sure to exert an effect on the catalytic activity. Combining the SEM and TEM results with the naphthalene conversions of the catalysts, it is obvious that the higher the $\mathrm{Ni}_{x} \mathrm{P}$ dispersion, the better the naphthalene HYD activity. Based on above results, these facts clearly indicated that the surface acidity of supported nickel phosphide catalysts played an important role on the adsorption of naphthalene for the HYD. And a more detailed comparison of the differences in the product distribution over these catalysts with various temperature is displayed in Fig. S10(a)-(e).† As we can see from Fig. S10, $\dagger$ an almost complete conversion of naphthalene into decalin was observed over the reaction temperature range of $250-330{ }^{\circ} \mathrm{C} .15 \mathrm{wt} \% \mathrm{Ni}_{x} \mathrm{P}-\mathrm{Al}-\mathrm{M}$ catalyst mostly converted naphthalene into decalin at lower temperature, in contrast with the $15 \mathrm{wt} \% \mathrm{Ni}-\mathrm{Al}-\mathrm{M}$ catalyst. It also can be obviously seen that the tetralin selectivity steadily increased with the further raise of reaction temperature along with the decrease of naphthalene conversion due to the equilibrium limitation of 15 wt $\% \mathrm{Ni}_{x} \mathrm{P}-\mathrm{MCM}-41$ and 15 wt $\% \mathrm{Ni}_{x} \mathrm{P}-(\mathrm{M}+\mathrm{Al})$ catalysts. At $270{ }^{\circ} \mathrm{C}$, the $15 \mathrm{wt} \% \mathrm{Ni}_{x} \mathrm{P}-\mathrm{MCM}-41$ catalyst showed a naphthalene conversion of $99.0 \%$ with the tetralin and decalin selectivities of 39.3 and $60.8 \%$, respectively. And at $330{ }^{\circ} \mathrm{C}$, the tetralin and decalins selectivities were almost $2: 1$ at the naphthalene conversion of $98.7 \%$. The $15 \mathrm{wt} \% \mathrm{Ni}_{x} \mathrm{P}-(\mathrm{M}+\mathrm{Al})$ catalyst showed a moderate level of naphthalene conversion and tetralin selectivity, compared with $15 \mathrm{wt} \% \mathrm{Ni}_{x} \mathrm{P}-\mathrm{MCM}-41$ and $15 \mathrm{wt} \% \mathrm{Ni}_{x} \mathrm{P}-\mathrm{Al}-\mathrm{M}$. Above results validate the fact that the acidity of the support plays a significant role in the HYD of aromatic molecules and the catalyst prepared by depositing $\mathrm{Ni}_{x} \mathrm{P}$ on acidic supports shows higher activity than the catalyst prepared by depositing $\mathrm{Ni}_{x} \mathrm{P}$ on non-acidic supports as reported elsewhere. So the higher activity of $\mathrm{Ni}_{x} \mathrm{P}-\mathrm{Al}-\mathrm{M}$, compared with the $15 \mathrm{wt} \% \mathrm{Ni}_{x} \mathrm{P}-\mathrm{MCM}-41$ and $15 \mathrm{wt} \% \mathrm{Ni}_{x} \mathrm{P}-(\mathrm{M}+\mathrm{Al})$ catalysts, can be attributed to the stronger surface acidity of the Al-M support which coupled with hydrogen spillover effect favoring the HYD of aromatics. The $15 \mathrm{wt} \% \mathrm{Ni}_{x} \mathrm{P}-\mathrm{Al}-\mathrm{M}$ catalysts exhibited high decalin selectivity at high naphthalene conversion level while the reference $0.5 \mathrm{wt} \% \mathrm{Pt}-\mathrm{Al}-\mathrm{M}$ catalyst showed a relatively low HYD activity towards naphthalene. This implied the high HYD abilities of the $\mathrm{Ni}_{x} \mathrm{P}-\mathrm{Al}-\mathrm{M}$ catalysts and may take the replace of noble metals in the future. Thus it is easy to understand and conclude that the naphthalene HYD activity is first related to the $\mathrm{Ni}_{x} \mathrm{P}$ dispersion. The second factor that affects the catalytic activity is the electron density of the $\mathrm{Ni}_{x} \mathrm{P}$ particles. Thirdly, the acid sites and hydroxyls provide additionally active sites and favour spillover hydrogen, which also contributes to HYD activity. Furthermore, long-term stability test for the 15 wt $\% \mathrm{Ni}_{x} \mathrm{P}-\mathrm{Al}-\mathrm{M}-(1.25)$ catalyst at $270{ }^{\circ} \mathrm{C}$ is displayed in Fig. S11. $\dagger$ As shown in Fig. S11, $\uparrow$ during the activity testing, catalysts have not shown deactivation trend on the whole, which indicated that $15 \mathrm{wt} \% \mathrm{Ni}_{x} \mathrm{P}-\mathrm{Al}-\mathrm{M}-(1.25)$ catalyst showed good activity and stability. In order to get rid of the influence of different exposed active sites on different catalysts, we chose TOF as a significant the activity of per active site in unit time. It is reported that the numbers of active sites on the $\mathrm{Ni}_{x} \mathrm{P}$ surfaces can be titrated by the adsorption of CO since CO species could effectively titrate active centers of $\mathrm{Ni}_{x} \mathrm{P}$ via the formation of $\pi$ back-bonding of higher-electron density $\mathrm{Ni}_{x} \mathrm{P}$ species, according to which the turnover frequency (TOF) values for the hydrotreating reactions can be calculated to gain an insight on the number of naphthalene molecules converted to decalin on a catalytic site per second. ${ }^{46}$ The corresponding CO chemisorption uptakes and turnover frequency (TOF) results based on CO adsorption are presented in the last two columns of Table S4. $\dagger$ Seen from the Table $54, \uparrow$ the TOFs of the all catalysts tested were nearly the same, as anticipated.

\subsection{Possible mechanism}

It has been widely reported that the naphthalene HYD occurred in two consecutive steps and a reaction pathway could be figured out as shown in Scheme 1: conversion to tetralin in the first step through sequential cis-addition steps of two dissociatively adsorbed hydrogen atoms, followed by further formation of decalin in the second step according to the following formula:

$$
\mathrm{C}_{10} \mathrm{H}_{8}+2 \mathrm{H}_{2} \rightarrow \mathrm{C}_{10} \mathrm{H}_{12}+3 \mathrm{H}_{2} \rightarrow \mathrm{C}_{10} \mathrm{H}_{18} \text { (ref. 44) }
$$

Decalin has two isomers, which are trans- and cis-decalin, and can be used as thermal stable jet fuel in extreme condition. Hence, the selectivity to decalin is used in our study as the main criterion to evaluate the catalytic performance. Pang et al.

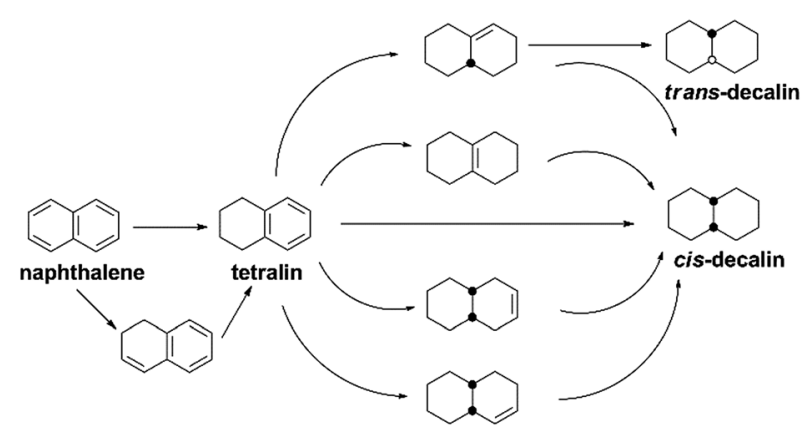

Scheme 1 Reaction pathway of naphthalene hydrogenation. 
studied naphthalene HYD and found that the HYD rate of naphthalene to tetralin was an order of magnitude faster than that of tetralin to decalin. ${ }^{47}$ Some evidence showed that olefins played an important role in the reaction scheme. Naphthalene react to $\Delta^{9,10}$-octalin, which is either directly hydrogenated to cis-decalin at high pressure or isomerized to intermediate $\Delta^{1,9}$ octalin. $\Delta^{1,9}$-octalin is, in turn, hydrogenated to cis- and transdecalin. Tetralin reacted directly with hydrogen to form cisdecalin, or through the intermediate $\Delta^{1,9}$-octalin. But tetralin could not convert directly into trans-decalin. It needed to convert to $\Delta^{1,9}$-octalin and then to trans-decalin. As aforementioned, $\Delta^{1,9}$-octalin is widely reported to be the most reactive intermediate product in the reaction tetralin $\rightarrow$ decalin, therefore, the formations of trans- or cis-decalin are closely related to this intermediate. Based on the conformation between the intermediate $\Delta^{1,9}$-octalin and the catalyst surface, the possible formation of trans- or cis-decalin could be inferred considering the syn nature of hydrogen addition, which means that when the $\mathrm{H}$ atoms are added to a double bond, both $\mathrm{H}$ atoms are always on the same side. ${ }^{48}$ Dokjampa et al. proposed that the formation mechanisms of trans- or cis-decalin depended on the hydrogen atom in position 10 facing towards or away from the catalyst surface. ${ }^{48}$ When the hydrogen atom in position 10 of this intermediate is oriented facing towards the catalyst surface, the HYD of the double bond results in the formation of cis-decalin, because hydrogen addition to a double bond is always syn (both $\mathrm{H}$ atoms are added on the same side). By contrast, when the hydrogen atom in position 10 is oriented facing away from the catalyst surface, the syn HYD addition results in the formation of trans-decalin. According to our results, the very good catalytic performance is due to the interaction between the support acid sites and the HYD sites on bifunctional catalysts and a possible reaction mechanism for the HYD of naphthalene on nickel phosphide catalyst can be proposed as depicted in Fig. 7. One side, $\mathrm{Ni}_{x} \mathrm{P}$ can be ascribed to the effects and behavior of the $\mathrm{P}$ sites and the formation of Ni-P bonds. First, in $\mathrm{Ni}_{x} \mathrm{P}$, the concentration of $\mathrm{Ni}$ is diluted by the presence of $\mathrm{P}$, the formation of $\mathrm{Ni}-\mathrm{P}$ bonds induces relatively minor perturbations in the electronic properties of nickel. ${ }^{\mathbf{9}}$ Namely, a weak ligand effect (minor stabilization of the Ni 3d levels and a small $\mathrm{Ni} \rightarrow \mathrm{P}$ light charge transfer) that allows a reasonably high activity for the dissociation of naphthalene and molecular hydrogen, ${ }^{49}$ forming spillover of activated hydrogen from HYD sites to the acidic support. Second, the number of exposed active $\mathrm{Ni}$ sites present in the surface decreases due to an ensemble effect of $\mathrm{P}$, which prevents the system from the deactivation. ${ }^{\mathbf{4 9}}$ Third, the $\mathrm{P}$ sites are not simple spectators and provide moderate bonding to the products of the decomposition of naphthalene and the $\mathrm{H}$ adatoms necessary for HYD. ${ }^{49} \mathrm{Ni}_{x} \mathrm{P}-\mathrm{Al}-\mathrm{M}$ is a highly active HDA catalyst by obeying Sabatier's principle: good bonding with the reactants, and moderate bonding with the products. On the other side, a possible explanation for the influence of the acidic sites in the HYD activity of the $\mathrm{Ni}_{x} \mathrm{P}-\mathrm{Al}-\mathrm{M}$ catalyst may be mainly related to the migration of electron charge. Detailed reasons are as follows: firstly, the surface acidity favored the adsorption of naphthalene since naphthalene can be taken as a Lewis base

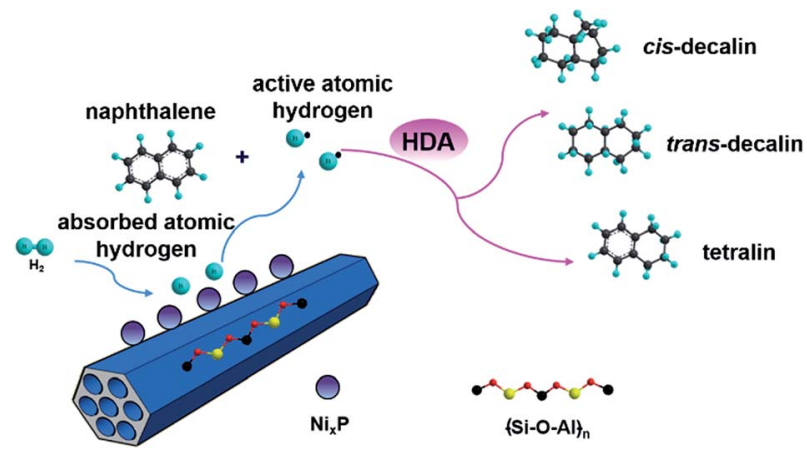

Fig. 7 Proposed reaction schematic of naphthalene HDA over highly active $\mathrm{Ni}_{x} \mathrm{P}-\mathrm{Al}-\mathrm{M}$ catalyst.

due to the enriched electron density on the aromatic ring with $\pi$-bonds. ${ }^{24}$ Secondly, the $\mathrm{Ni}_{x} \mathrm{P}$ supported on the acidic Al-M surface might be electron-deficient due to the electron charge transfer from $\mathrm{Ni}_{x} \mathrm{P}$ to acidic sites, leading to changing the surface charge density of nickel and formation of electron deficient metal sites in close vicinity of the support acid sites, increasing the activity. Thus the adsorption of naphthalene on the electron-deficient nickel might be enhanced due to the enhanced electron donor from the naphthalene to nickel atoms. Namely, the electron-deficient surface nickel atoms on the acidic, which favored the donation of electron charges from naphthalene to the electron-deficient $d$ orbitals of surface nickel. Apparently, the surface acidity also favored the adsorption and activation of aromatic rings. ${ }^{50}$

\section{Conclusions}

In summary, using $\mathrm{Al}-\mathrm{M}$ as the support, $\mathrm{Ni}_{x} \mathrm{P}-\mathrm{Al}-\mathrm{M}$, a series of supported nickel phosphide catalysts with different Ni/P molar ratios and loadings have been prepared by a temperatureprogrammed reduction method. The naphthalene HDA result shows that both the Ni/P ratio and loading of the catalysts have profound effect on the naphthalene HYD performance. The results showed that the catalyst with initial Ni/P molar ratios of and $15 \mathrm{wt} \%$ loading displayed the highest HDA activity as well as $99.0 \%$ of selectivity of decalin at $270{ }^{\circ} \mathrm{C}$, which is even higher than that of $0.5 \mathrm{wt} \% \mathrm{Pt}-\mathrm{Al}-\mathrm{M}$ catalyst. As a comparison, the HDA performance of various catalysts were also examined. The results revealed that the presence of framework aluminum favors HDA processes and a synergistic effect between nickel phosphide and the suitable acidity resulted in an improvement of the catalytic activity. These results indicated that the catalyst performance is related to its acid property, pore structure, high dispersion, the number of active sites, and the intimate contact between $\mathrm{Ni}_{x} \mathrm{P}$ and the support. Finally, the possible reaction pathway of naphthalene HYD on nickel phosphide catalysts was proposed. Considering the high HDS, HDN, and HDA activities of nickel phosphide catalysts, $\mathrm{Ni}_{x} \mathrm{P}-\mathrm{Al}-\mathrm{M}$ can be considered as a very efficient HYD catalyst to produce clean fuels. In our future work, the catalytic activities of nickel phosphide catalysts for HDS and HDA of jet fuel will be studied. 


\section{Acknowledgements}

This work was financially supported by the NSFC (21376123, U1403293, 21603107), MOE (IRT-13R30 and 113016A), NSFT (15JCQNJC05500), and the Research Fund for 111 Project (B12015).

\section{References}

1 A. Zhao, X. F. Zhang, X. Chen, J. C. Guan and C. H. Liang, J. Phys. Chem. C, 2010, 144, 3962-3967.

2 C. S. Song and X. L. Ma, Appl. Catal., B, 2003, 41, 207-238.

3 S. De, J. G. Zhang, R. Luque and N. Yan, Energy Environ. Sci., 2016, 9, 3314-3347.

4 S. B. Qiu, X. Zhang, Q. Y. Liu, T. J. Wang, Q. Zang and L. L. Ma, Catal. Commun., 2013, 42, 73-78.

5 A. C. A. Monteiro-Gezork, A. Effendi and J. M. Winterbottom, Catal. Today, 2007, 128, 63-73.

6 Q. Wang, X. C. Cai, Y. Q. Liu, J. Y. Xie, Y. Zhou and J. Wang, Appl. Catal., B, 2016, 189, 242-251.

7 W. T. Yu, M. D. Porosoff and J. G. Chen, Chem. Rev., 2012, 112, 5780-5817.

8 B. Pawelec, R. Mariscal, R. M. Navarro, S. van Bokhorst, S. Rojas and J. L. G. Fierro, Appl. Catal., A, 2002, 225, 223237.

9 N. Hiyoshi, A. Yamaguchi, C. V. Rode, O. Sato and M. Shirai, Catal. Commun., 2009, 10, 1681-1684.

10 S. T. Oyama, J. Catal., 2003, 216, 343-352.

11 S. F. Yang, C. H. Liang and R. Prins, J. Catal., 2006, 237, 118130.

12 R. Wang and K. J. Smith, Appl. Catal., A, 2009, 361, 18-25.

13 X. P. Duan, Y. Teng, A. J. Wang, V. M. Kogan, X. Li and Y. Wang, J. Catal., 2009, 261, 232-240.

14 A. H. Janssen, A. J. Koster and K. P. de. Jong, J. Phys. Chem. B, 2002, 106, 11905-11909.

15 J. C. Groen, W. D. Zhu, S. Brouwer, S. J. Huynink, F. Kapteijn, J. A. Moulijn and J. Pérez-Ramírez, J. Am. Chem. Soc., 2007, 129, 355-360.

16 J. Panpranot, K. Pattamakomsan, J. G. Goodwin Jr and P. Praserthdam, Catal. Commun., 2004, 5, 583-590.

17 S. Nassreddine, S. Casu, J. L. Zotin, C. Geantet and L. Piccolo, Catal. Sci. Technol., 2011, 1, 408-412.

18 J. I. Park, J. K. Lee, J. Miyawaki, Y. K. Kim, S. H. Yoon and I. Mochida, Fuel, 2011, 90, 182-189.

19 M. X. Du, Z. F. Qin, H. Ge, X. K. Li, Z. J. Lu and J. G. Wang, Fuel Process. Technol., 2010, 91, 1655-1661.

20 K. B. Sidhpuria, P. A. Parikh, P. Bahadur, B. Tyagi and R. V. Jasra, Catal. Today, 2009, 141, 12-18.

21 L. J. Simon, J. G. van Ommen, A. Jentys and J. A. Lercher, Catal. Today, 2002, 73, 105-112.

22 T. D. Tang, C. Y. Yin, L. F. Wang, Y. Y. Ji and F. S. Xiao, J. Catal., 2008, 257, 125-133.

23 B. Pawelec, R. Mariscal, R. M. Navarro, S. van Bokhorst, S. Rojas and J. L. G. Fierro, Appl. Catal., A, 2002, 225, 223-237.
24 R. S. Araujo, D. C. S. Azevedo, C. L. Cavalcante Jr, A. JimenezLopez and E. Rodriguez-Castellon, Microporous Mesoporous Mater., 2008, 108, 213-222.

25 B. J. Liu, Q. L. Meng, H. Wang and Q. M. Meng, Acta Phys.Chim. Sin., 2010, 26, 3257-3262.

26 J. A. Cecilia, A. Infantes-Molina, E. Rodríguez-Castellón and A. Jiménez-López, J. Catal., 2009, 263, 4-15.

27 Y. Y. Shu and S. T. Oyama, Carbon, 2005, 43, 1517-1532.

28 X. Q. Wang, P. Clark and S. T. Oyama, J. Catal., 2002, 208, 321-331.

29 M. S. Li, K. N. Hui, K. S. Hui, S. K. Lee, Y. R. Cho, H. Lee, W. Zhou, S. Cho, C. Y. H. Chao and Y. Y. Li, Appl. Catal., B, 2011, 107, 245-252.

30 T. Klimova, M. Calderón and J. Ramıírez, Appl. Catal., A, 2003, 240, 29-40.

31 D. Li, P. Bui, H. Y. Zhao, S. T. Oyama, T. Dou and Z. H. Shen, J. Catal., 2012, 290, 1-12.

32 D. S. Zhang, R. J. Wang and X. X. Yang, Catal. Commun., 2011, 12, 399-402.

33 H. Kosslick, G. Lischke, B. Parlitz, W. Storek and R. Fricke, Appl. Catal., A, 1999, 184, 49-60.

34 K. Góra-Marek and J. Datka, Appl. Catal., A, 2006, 302, 104-109. 35 M. V. Landau, M. Herskowitz, T. Hoffman, D. Fuks, E. Liverts, D. Vingurt and N. Froumin, Ind. Eng. Chem. Res., 2009, 48, 5239-5249.

36 J. H. Jang, S. C. Lee, D. J. Kim, M. Kang and S. J. Choung, Appl. Catal., A, 2005, 286, 36-43.

37 T. Chen, B. L. Yang, S. S. Li, K. L. Wang, X. D. Jiang, Y. Zhang and G. W. He, Ind. Eng. Chem. Res., 2011, 50, 11043-11048.

38 T. I. Korányi, Z. Vít, D. G. Poduval, R. Ryoo, H. S. Kim and E. J. M. Hensen, J. Catal., 2008, 253, 119-131.

39 X. Li, Y. L. Zhang, A. J. Wang, Y. Wang and Y. K. Hu, Catal. Commun., 2010, 11, 1129-1132.

40 S. J. Sawhill, K. A. Layman, D. R. Van Wyk, M. H. Engelhard, C. M. Wang and M. E. Bussell, J. Catal., 2005, 231, 300-313.

41 S. H. Hu, M. W. Xue, H. Chen and J. Y. Shen, J. Chem. Eng., 2010, 162, 371-379.

42 M. Rozwadowski, M. Lezanska, J. Wloch, K. Erdmann, R. Golembiewski and J. Kornatowski, Chem. Mater., 2001, 13, 1609-1616.

43 Y. K. Lee, Y. Y. Shu and S. T. Oyama, Appl. Catal., A, 2007, 322, 191-204.

44 X. F. Zhang, Q. M. Zhang, A. Q. Zhao, J. Guan, D. M. He, H. Q. Hu and C. H. Liang, Energy Fuels, 2010, 24, 3796-3803. 45 M. J. Luo, Q. F. Wang, G. Z. Li, X. W. Zhang, L. Wang and T. Jiang, Catal. Sci. Technol., 2014, 4, 2081-2090.

46 Y. K. Lee and S. T. Oyama, J. Catal., 2006, 239, 376-389.

47 M. Pang, C. Y. Liu, W. Xia, M. Muhler and C. H. Liang, Green Chem., 2012, 14, 1272-1276.

48 S. Dokjampa, T. Rirksomboon, S. Osuwan, S. Jongpatiwut and D. E. Resasco, Catal. Today, 2007, 123, 218-223.

49 P. Liu, J. A. Rodriguez, T. Asakura, J. Gomes and K. Nakamura, J. Phys. Chem. B, 2005, 109, 4575-4583.

50 V. R. Choudhary and K. Mantri, Langmuir, 2000, 16, 7031-7037. 